\title{
Upper Mantle Structure of Western North America from Apparent Velocities of $P$ Waves ${ }^{1}$
}

\author{
Mansour Niazi and Don L. Anderson \\ Seismological Laboratory \\ California Institute of Technology, Pasadena
}

\begin{abstract}
In a study of variation of the compressional velocity with depth in the $C$ region of the upper mantle in western North America, we determined apparent velocities of first arrivals across the Tonto Forest array in Arizona for about 70 shallow-focus earthquakes. The epicenters ranged from $10^{\circ}$ to $30^{\circ}$ in distance and were mostly south of the array. The method gives the slope of the travel-time curve directly, the parameter required for a velocity-depth determination. For this distance range we found that although the slope of the $P$ wave travel-time curve decreased substantially with distance, i.e., increasing apparent velocity, the variation was not uniform. Two relatively abrupt changes were observed at distances of about $17^{\circ}$ and $24^{\circ}$. These are most readily interpreted as two second-order discontinuities in the region of the mantle above $1000 \mathrm{~km}$. Assuming an average crustal structure as derived from seismic refraction measurements and taking the uppermost $200 \mathrm{~km}$ of the mantle given by Gutenberg or Jeffreys, we investigated various possible forms of variation of the $P$ wave velocity with depth. The discontinuities in the rate of change of velocity with depth which cause the observed breaks in the apparent velocity curve are found to be at depths of about 320 and $640 \mathrm{~km}$. Although no absolute times are required in the method, the travel times for the various derived models are computed and compared with standard tables.
\end{abstract}

Introduction. The most abundant and direct source of data regarding the structure of the earth's interior is the travel times of various seismic body phases. The Herglotz-Wiechert method used in the interpretation of body waves requires a knowledge of $d t / d \Delta$ as a function of distance. This is ordinarily obtained from the slope of the observed travel-time curve and involves the smoothing of observations made at seinnic observatories which are over different crustal structures.

Application of this method has yielded a number of velocity-depth profiles which are similar except in the upper $1000 \mathrm{~km}$ of the mantle and in a small region of the transition zone of the core. There are various reasons for the differences in the derived structures of the upper mantle, including real variations, errors of apparent velocity introduced by smoothing of seattered data, and disagreement in the interpretation of data. The existence or absence of low-velocity layers and discontinuities are the main differences between the standard models of Gutenberg, Lehmann, and Jeffreys. These are also the complications which lead

3 Contribution 1346, Division of Geological Seienees, California Institute of Technology. to theoretical difficulties in the body wave travel-time method. The models of Gutenberg and Lehmann have an upper mantle lowvelocity region; Jeffreys' model does not. The models of Lehmann and Jeffreys have a strong discontinuity above a depth of $400 \mathrm{~km}$; Gutenberg's model is smooth throughout the mantle. The scatter of travel-time data and the complicated amplitude pattern in the epicentral region of $15^{\circ}$ to about $28^{\circ}$ is partly responsible for the ambiguities of interpretation.

The first evidence for the sudden change of the slope of the travel-time curve of $P$ waves near the epicentral distance of $20^{\circ}$ was presented by Byerly [1926]. In a later analysis of the Nevada earthquake of December 20, 1932, with considerably more data Byerly [1935] noted that the $P$ wave travel times showed two discontinuities at epicentral distances of about $17^{\circ}$ and $28^{\circ}$, the latter being clearer. In the last few years, measurements have revealed additional evidence for discontimuities in the upper $1000 \mathrm{~km}$ of the mantle. A brief account of these observations is summarized by Anderson [1965].

In recent years a number of seismometer arrays have been installed around the world, some having linear dimensions of several kilometers. 
The primary purpose of thene instulations is the improvement of signal-to-nois ratio so that small events can bo delectal. Fach array is practionly equivilent to sereral stations with

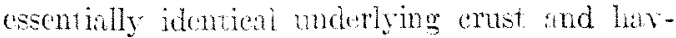
ing the same azimm from the tricenter. They ean therefore be ned ior direct notsurement

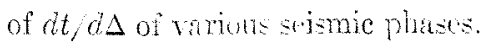

The linear extent of an array which ean be uef for this purpose is restricted on one hand by the recuired resolution of the time of arrival of the signal and on the other hand by the desired homogencity of the nuderlying crust and upper mantle. Although the later restrietion depends on the deyree of lateral variation in the uppermost 50 to $100 \mathrm{~km}$ of the earth's structure, the former varies with the phase under considemion and with epientril distince.

The scionogtams of 69 shallow enrthquates, selected trum among more than 200, and one undergromd explosion, reonded at Tonto Forest Seismological oberwatory (TFSO), Arizona, were sudied. The dtad of the lirst arrivals in the $P$ gromp of thene enthqukes across the arry were meneured and eximined for

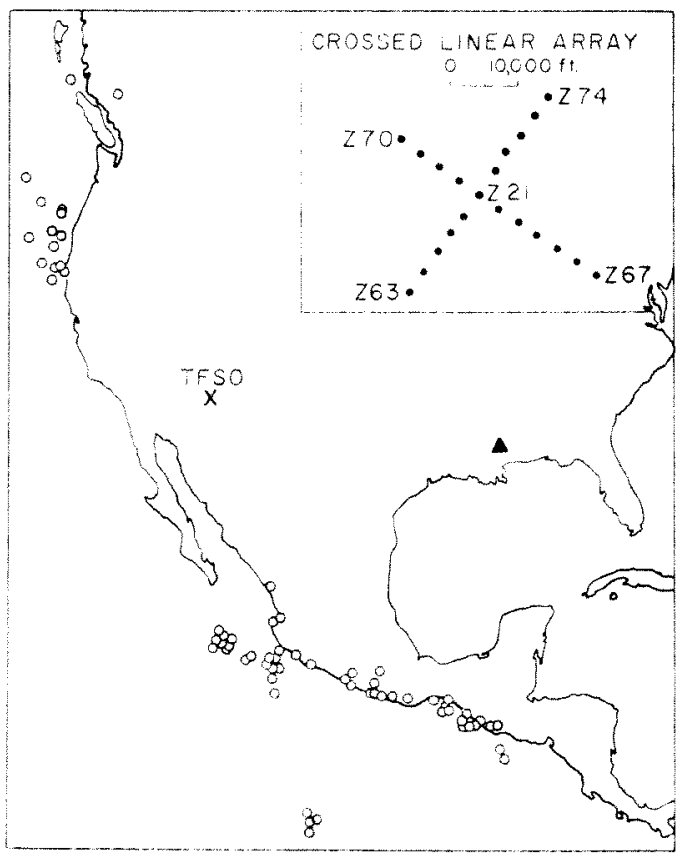

Fig. 1. Loration of ejichters and array. Insert shows the gomery ad orititetion of the array. possible indications of discontimuities in the region of the inantle between 225 and 800 $\lim$ depth.

Details of the installation and operation at TSFO are published in the semiannual progress reports of the observatory. Datit are read from the recordings of the short-period vertical scismometers installed at the end points of a crosed linear array $(Z 63, Z 67, Z 70$, and $Z 74$ in Figure 1). The array consists of two perpendicnlar lines, atch of which is approximatcly 10 km long, and contains eleven seismometers. The instruments are of the Johnson-Mitheson type, running with unusually high magnifiction of $650 \mathrm{~K}$ at $1 \mathrm{cps}$.

The recordings of first $P$ arrivals of two of the earthquaks are reproduced in Figure 2. The first carthqunke has a manitude of 5.4 and is loeated $13.3^{\circ}$ toward the northwest of the arriy: the second has an epicentral distance of $20.3^{\circ}$ to the southerst of $\mathrm{TSFO}$ and a mignitude of 4.1 . The clear later arrivals are an additional sonrce of information regarding structure of the upper mante which we do not we in the present paper because of uncertainty is to the depths of the sources.

Arulysis of data. The data are listed in Tabe 1. All but the numbers jisted in the last column are reproduced from the Geotch

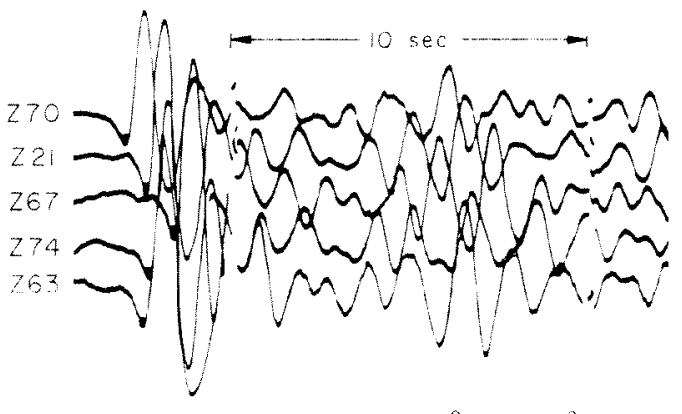

June $3,1964, \quad \Delta-13,3, \phi=30^{\circ}$

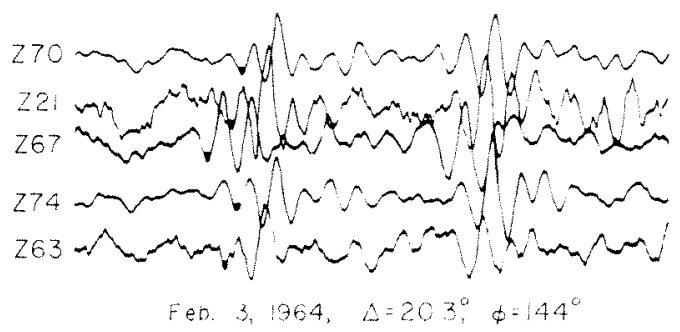

Fig. 2. Reprosentative seistnogrums. 
TABLE 1. List of Earthquakes for Which $d t / d \Delta$ Is Measured

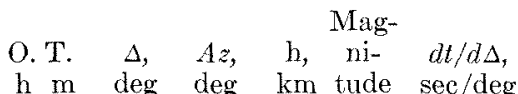
1963

$\begin{array}{lrrrrrrrr}\text { oct. } & 4 & 08 & 34 & 22.3 & 141 & 41 & 4.5 & 10.9 \\ & 7 & 05 & 35 & 14.6 & 172 & 33 & 4.7 & 13.0 \\ & 11 & 09 & 51 & 17.0 & 161 & 33 & 4.6 & 12.3 \\ & 13 & 16 & 45 & 14.4 & \text { SE } & 50 & 4.8 & 11.7 \\ & 19 & 01 & 04 & 24.1 & \text { SSE } & 34 & 4.3 & 8.8 \\ & 29 & 07 & 01 & 12.3 & \text { NW } & 38 & 4.7 & 13.8 \\ \text { Nov. } & 14 & 09 & 05 & 24.7 & 136 & 33 & 4.9 & 9.0 \\ & 20 & 01 & 13 & 23.5 & 330 & 39 & 4.0 & 10.2 \\ \text { Dec. } & 3 & 12 & 23 & 17.0 & 160 & 33 & 4.0 & 11.9 \\ & 4 & 04 & 18 & 15.0 & 169 & 33 & 4.8 & 13.8 \\ & 12 & 00 & 38 & 16.0 & 165 & 33 & 4.5 & 13.0 \\ & 15 & 16 & 54 & 21.7 & 142 & 35 & 4.2 & 11.2 \\ & 22 & 01 & 20 & 25.8 & 136 & 33 & 4.4 & 9.1 \\ & 25 & 23 & 02 & 15.5 & 170 & 33 & 3.7 & 13.7 \\ 28 & 06 & 57 & 26.2 & 134 & 33 & 4.5 & 9.4 \\ 29 & 04 & 34 & 15.9 & 161 & 33 & 3.8 & 11.9 \\ & 06 & 22 & 16.3 & 161 & 33 & 4.4 & 13.8 \\ 31 & 21 & 41 & 20.7 & 145 & 33 & 4.3 & 11.1\end{array}$
1964

Jan.

$\begin{array}{rllll}1 & 09 & 43 & 16.7 & 162 \\ & 19 & 45 & 12.2 & 156 \\ 6 & 23 & 37 & 15.2 & 169 \\ 11 & 00 & 40 & 21.3 & 144 \\ 17 & 22 & 18 & 20.9 & 144 \\ 18 & 14 & 40 & 24.5 & 137 \\ 20 & 20 & 30 & 20.8 & 143 \\ 23 & 01 & 42 & 16.1 & 167 \\ 28 & 04 & 56 & 14.5 & 313 \\ 31 & 17 & 07 & 19.6 & 334\end{array}$

$\begin{array}{lll}33 & 4.4 & 13.0\end{array}$

$\begin{array}{lll}33 & 4.0 & 13.8\end{array}$

$\begin{array}{lll}33 & 4.1 & 13.8\end{array}$

$\begin{array}{lll}33 & 4.5 & 10.7\end{array}$

$\begin{array}{lll}33 & 4.2 & 11.1\end{array}$

$\begin{array}{lll}33 & 4.6 & 9.4\end{array}$

$\begin{array}{lll}33 & 4.3 & 11.1\end{array}$

$\begin{array}{lll}33 & 3.8 & 13.4\end{array}$

$\begin{array}{lll}17 & 4.5 & 14.2\end{array}$

$\begin{array}{lll}14 & 4.2 & 11.1\end{array}$

Feb.

$\begin{array}{llll}02 & 00 & 26.0 & 137\end{array}$

$\begin{array}{llll}17 & 34 & 20.3 & 144\end{array}$

$\begin{array}{lllll}8 & 09 & 59 & 26.8 & 133\end{array}$

$\begin{array}{lllll}9 & 10 & 49 & 28.9 & 134\end{array}$

$\begin{array}{llllll}13 & 02 & 22 & 26.6 & 160\end{array}$

$\begin{array}{llll}02 & 30 & 26.8 & 161\end{array}$

$\begin{array}{llll}02 & 39 & 27.4 & 162\end{array}$

$\begin{array}{lllll}14 & 12 & 07 & 14.7 & 313\end{array}$

$\begin{array}{lllll}18 & 09 & 07 & 26.1 & 161\end{array}$

$\begin{array}{lllll}20 & 12 & 03 & 25.7 & 136\end{array}$

$\begin{array}{lllll}21 & 03 & 15 & 25.4 & 134\end{array}$

$\begin{array}{lllll}26 & 20 & 32 & 12.1 & 303\end{array}$

$\begin{array}{lllll}27 & 11 & 35 & 16.6 & 155\end{array}$

$\begin{array}{llllll}\text { March } & 3 & 07 & 04 & \mathbf{1 6 . 3} & 311\end{array}$

$\begin{array}{llll}20 & 02 & 12.5 & 302\end{array}$

$\begin{array}{lllll}5 & 11 & 42 & 12.2 & 299\end{array}$

$\begin{array}{lllll}8 & 19 & 12 & 14.2 & 158\end{array}$

$\begin{array}{llll}19 & 44 & 14.0 & 156\end{array}$

$\begin{array}{lllll}10 & 09 & 04 & 15.2 & 170\end{array}$

$\begin{array}{llllll}12 & 18 & 35 & 14.3 & 171\end{array}$

$\begin{array}{lllll}13 & 11 & 54 & 28.5 & 133\end{array}$

$\begin{array}{llll}21 & 08 & 27.0 & 132\end{array}$

$\begin{array}{lllll}18 & 11 & 39 & 26.1 & 134\end{array}$
TABLE 1. (Continued)

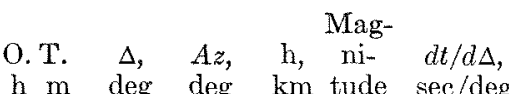
Date $\mathrm{h} m$ deg deg $\mathrm{km}$ tude sec/deg

\begin{tabular}{|c|c|c|c|c|c|c|c|}
\hline & 23 & $06 \quad 12$ & 18.6 & 161 & 33 & 4.0 & 11.6 \\
\hline & 24 & 0937 & 21.4 & 327 & 22 & 4.2 & 10.6 \\
\hline & 28 & 1008 & 11.5 & 38 & 16 & 5.1 & 14.0 \\
\hline \multirow[t]{2}{*}{ April } & 3 & 0556 & 24.4 & 136 & 33 & 4.2 & 9.4 \\
\hline & 8 & 0338 & 23.4 & 317 & 33 & 4.3 & 9.8 \\
\hline \multirow[t]{6}{*}{ June } & 3 & 1141 & 15.0 & 169 & 33 & 4.1 & 13.7 \\
\hline & & 1350 & 13.3 & 301 & 33 & 5. & 14.7 \\
\hline & 4 & 0428 & 19.2 & 148 & 22 & 4. & 10.9 \\
\hline & 20 & $17 \quad 12$ & 16.5 & 160 & 28 & 5.5 & 13.0 \\
\hline & & 1935 & 16.3 & 160 & 33 & 4.5 & 13.0 \\
\hline & 24 & 1513 & 19.5 & 147 & 33 & 4.4 & 11.6 \\
\hline \multirow[t]{5}{*}{ July } & 6 & 0722 & 18.6 & 146 & 100 & 6.3 & 11.3 \\
\hline & 14 & 1247 & 13.6 & 308 & 33 & 5.4 & 14.6 \\
\hline & 20 & 1849 & 14.6 & 172 & 33 & 5.1 & 13.0 \\
\hline & 21 & 0107 & 14.8 & 172 & 33 & 5.3 & 13.4 \\
\hline & & 0341 & 15.5 & 173 & 33 & 3.7 & 13.2 \\
\hline \multirow[t]{2}{*}{ Aug. } & 13 & 0635 & 14.1 & 309 & 33 & 4.9 & 14.0 \\
\hline & & 0850 & 13.7 & 310 & 33 & 4.9 & 14.0 \\
\hline Oct. & 22 & Salmon & 18.5 & 94 & & & 11.9 \\
\hline
\end{tabular}

monthly bulletins and are based on the USCGS preliminary reports. The measured slopes are given in the last column. Only two of the earthquakes have listed focal depths of over $50 \mathrm{~km}$, for which appropriate corrections in the epicentral distances are made.

The distribution of the epicenters around TSFO is shown in Figure 1. The epicentral distances range from $12^{\circ}$ to $28^{\circ}$. About $20 \%$ of the azimuths are to the northwest; the remaining $80 \%$ stretch from due south to the southeast of TSFO.

Figure 3 is a plot of the measured slopes. The point marked by a triangle belongs to the Salmon underground explosion in Mississippi $\left(\Delta=18.5^{\circ}, A z=93.7^{\circ}\right)$. For this explosion the slope was measured on the horizontal components.

In the same figure the tabulated Jeffreys slopes $d T / d \Delta$ for shallow earthquakes ( $h=$ $\left.0.00 r_{0}\right)$, computed from Jeffreys and Bullen's [1958] tables are smoothed and shown by the dashed line. It is noted that a variation of slopes such as the one given by the Jeffreys model is not in close agreement with our measured values. Our data fail to indicate any sudden decrease in $d T / d \Delta$ at $\Delta=20^{\circ}$. Instead, there 


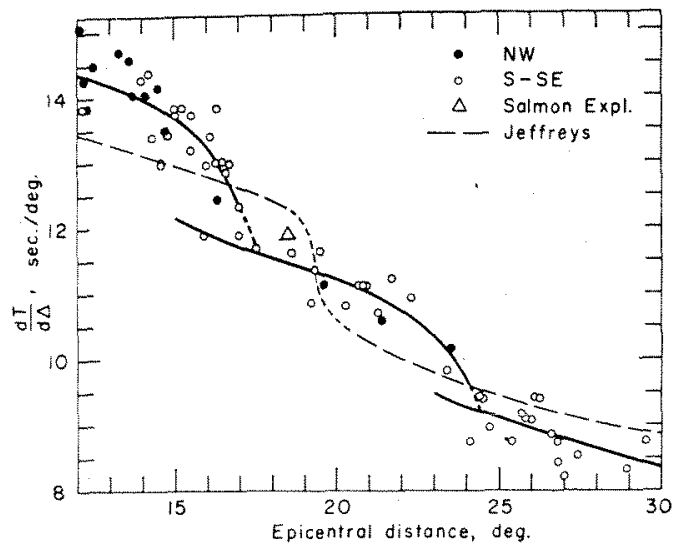

Fig. 3. Apparent reciprocal velocity versus distance. Velocity of model $Z$ is based on the segmented curve. The dashed curve is for the Jeffreys-Bullen model. Solid circles represent earthquakes located to the northwest of TFSO. The azimuths of earthquakes shown by hollow circles range from due south to southwest.

are indications that the assumed discontinuity at this distance is the compounded effect of the gradual decrease of the slope in the epicentral range between $15^{\circ}$ and $25^{\circ}$ which may include two less-pronounced discontinuities at epicentral distances of about $17^{\circ}$ and $24^{\circ}$.

Evidence for the existence of twin discontinuities with close correspondence to the ones suggested here have previously been presented by a number of investigators (see, for example, Doyle and Webb [1963]). With the commonly used technique of a few observations several degrees apart, it is extremely difficult to see the fine structure of the travel-time curve. Furthermore, when the observed travel-time points are smoothed, information dependent on the slope is lost.

The data presented in Figure 3, though illustrating the general trend, are quite scattered. This is in particular true for distances of less than $15^{\circ}$. Most of the earthquakes in this range are from off the coast of northern California and Oregon (solid circles). Paths of these earthquakes traverse the anomalous region underlying the Sierra Nevadas. Also some scattering results from the fact that $P_{n}$ may still appear as the first arrival. Lehmann [1964] observed that $P_{n}$ to the northeast of the Gnome explosion was a first arrival to epicentral distances as far as $19^{\circ}$. The $P_{n}$ velocity also varies rather rapidly in different regions of the western United States. Large-amplitude later arrivals may also have been picked as first arrivals.

Other factors contributing to the scatter are orrors in measurements and uncertainty in the epicentral distances. By analyzing only superior seismograms with low background noise and prominent first arrivals we attempted to minimize reading errors. Nevertheless, such errors may result in uncertainties as large as 1.0 sec/deg in the measured slopes. More accurate location, on the other hand, requires an even distribution of recording stations around the epicenter. This is not realized for the earthquakes under consideration, because of their geographic location. 'A study of this nature, therefore, should include a large number of observations so that a statistical treatment of the data is possible.

Alternative methods were adopted for smoothing the data before interpretation. In the first method all the observations were fitted by a single least-squares polynomial of degree 9 , giving a standard error of estimate of 0.43 sec/deg. In the second method the data were treated in three groups with breaks at distances of $17^{\circ}$ and $24^{\circ}$. Each group was fitted by a polynomial of degree 5 . The standard error of estimate for the whole range in the latter case is reduced to $0.35 \mathrm{sec} / \mathrm{deg}$. The discontinuous solid curve in Figure 3 resulted from the second procedure.

Because of the uncertainty of the first arrivals and the high scattering of the data at distances of less than $15^{\circ}$, we made use of two well-established models for depths corresponding to this epicentral range. The uppermost 200 $\mathrm{km}$ of the mantle is assumed to have the $P$ velocities suggested by Jeffreys (see Bullen [1963]) or by Gutenberg [1959]. On the basis of preliminary results of recent seismic refraction work in the recording region [Warren et al., 1965], a single-layered crust of $30-\mathrm{km}$ thickness, having an average compressional velocity of $6.1 \mathrm{~km} / \mathrm{sec}$, is also assumed.

Under these assumptions and with a choice of continuous or discontinuous treatment of the data, a number of possible velocity-depth profiles are derived for depths up to $800 \mathrm{~km}$. The method of successive stripping is applied so that, before application of the HerglotzWiechert formulas, 


$$
\ln \frac{r_{0}}{r_{1}}=\frac{1}{\pi} \int_{0}^{\Delta_{8}} \cosh ^{-1} \frac{p}{p_{1}} d \Delta \quad \frac{v_{1}}{r_{1}}=\frac{V}{r_{0}}
$$

the parameters involved, i.e., $\Delta, r_{0}$, and $r_{I}$, are properly reduced to those of the stripped earth. Here $r_{o}$ is the radius of the earth, $p$ the parameter of the ray (equivalent to the slope of travel-time curve), $v_{1}$ the velocity at the bottom of the ray $\left(r=r_{1}\right)$ emerging at an epicentral distance $\Delta_{1}$ and having the parameter $p_{2}, V$ is the apparent surface velocity at distance $\Delta$.

The resuits of the computations are summarized in Table 2. The variation of $P$ wave velocity in the uppermost $800 \mathrm{~km}$ of the mantle derived here and those suggested by Jeffreys and Gutenberg are compared in Figure 4. Models $X$ and $Y$ are constructed on the basis of the hypothesis of gradual decrease of $d t / d \Delta$ in the epicentral range of $15^{\circ}$ to $30^{\circ}$ and differ in the assumed structures between the $\mathrm{M}$ discontimuity and $225-\mathrm{km}$ depth. In this interval $X$ coincides wh the Jefireys model and $Y$ coincides with that of Gutenberg. Model Z also has a Gutenberg upper mantle, but the velocities between depths of 225 and $800 \mathrm{~km}$ are based on a $d / d \Delta$ curve which has two discontinuities at distances of $17^{\circ}$ and $24^{\circ}$. The depths corresponding to these discontinuities are close to 320 and $640 \mathrm{~km}$.

Discussion of results. As is apparent in Figure 4 , all three models begin as the continuation of either the Jeffreys or Gutenberg upper mantle (according to the assumptions made in the preceding section) from a depth of about $225 \mathrm{~km}$. For much of the profile, models $X$ and $Y$ represent an average to the Jeffreys and Cutenberg velocities and, together with model $Z_{3}$ converge to a value that is higher by about $0.2 \mathrm{~km} / \mathrm{sec}$ at a depth of $800 \mathrm{~km}$.

In the sectional smoothing of the data, one point at the epicentral distance of $15.9^{\circ}$, for which the observed $d t / d \Delta$ is $12.9 \mathrm{sec} / \mathrm{deg}$, has been assumed to be a second arrival and is thus combined with the observations between $17^{\circ}$ and $24^{\circ}$ (see Figure 3). There is some arbitrariness in the way different parts of the curve meet. The present data are not aceurate enough to permit us to decide whether each portion continues along the dash-dot tail to join the adjacent portion smoothly or whether there is some overlapping. Clear later arrivals on some
TABLE 2. $P$ Wave Velocity Distribution in the Upper Mantle between Depths of 225 and 800 Kilometers Derived for Models $X, Y$, and $Z$ For comparison, at some depths corresponding Jeffreys and Gutenberg velocities are also listed.

\begin{tabular}{rrrrrr}
\hline \multicolumn{5}{c}{ Velocity, km/sec } \\
Depth, & \multicolumn{5}{c}{} \\
\cline { 2 - 5 } & Jeffreys & $X$ & Gutenberg & $Y$ \\
\hline 0 & 6.1 & 6.1 & 6.1 & 6.1 & 6.1 \\
30 & 6.1 & 6.1 & 6.1 & 6.1 & 6.1 \\
30 & 7.75 & & 8.08 & & \\
60 & 7.84 & & 7.87 & & \\
100 & 7.95 & & 7.83 & & \\
160 & 8.13 & & 8.00 & & \\
200 & 8.26 & & 8.12 & & \\
225 & 8.34 & & 8.18 & & \\
240 & & 8.38 & & 8.24 & 8.25 \\
260 & & 8.44 & & 8.33 & 8.32 \\
280 & & 8.52 & & 8.41 & 8.42 \\
300 & 8.58 & 8.60 & 8.51 & 8.50 & 8.53 \\
320 & & 8.68 & & 8.59 & 8.64 \\
340 & & 8.77 & & 8.68 & 8.83 \\
360 & & 8.86 & & 8.78 & 8.94 \\
380 & & 8.96 & & 8.88 & 9.04 \\
400 & 8.90 & 9.05 & 9.00 & 8.98 & 9.13 \\
420 & & 9.15 & & 9.08 & 9.21 \\
440 & & 9.25 & & 9.18 & 9.29 \\
460 & & 9.35 & & 9.29 & 9.38 \\
480 & & 9.45 & & 9.40 & 9.46 \\
500 & & 9.55 & 9.49 & 9.50 & 9.55 \\
520 & & 9.66 & & 9.61 & 9.65 \\
540 & 9.91 & 9.77 & & 9.73 & 9.74 \\
560 & & 9.87 & & 9.84 & 9.84 \\
580 & & 9.98 & & 9.95 & 9.94 \\
600 & 10.25 & 10.09 & 9.99 & 10.06 & 10.05 \\
620 & & 10.20 & & 10.18 & 10.16 \\
640 & & 10.31 & & 10.29 & 10.28 \\
660 & & 10.42 & & 10.41 & 10.50 \\
680 & & 10.54 & & 10.52 & 10.62 \\
700 & & 10.65 & & 10.63 & 10.74 \\
720 & & 10.76 & & 10.75 & 10.85 \\
740 & & 10.88 & & 10.86 & 10.95 \\
760 & & 10.99 & & 10.97 & 11.05 \\
780 & & 11.10 & & 11.07 & 11.14 \\
800 & 11.00 & 11.21 & 11.00 & 11.18 & 11.24 \\
& & & & & \\
& & & & & \\
\hline & & & & \\
\hline
\end{tabular}

of the records suggest that the travel-time curve is multivalued.

For the sake of computational convenience, it is assumed that the neighboring sections of the discontinuous curve overlap slightly. The corresponding jumps in the velocity profile are quite small $(0.03$ and $0.06 \mathrm{~km} / \mathrm{sec}$ at 320 - and $640-\mathrm{km}$ depths, respectively) and, in the absence of other evidence such as reflections from such first-order discontinuities, may be ignored. In sketching Figure 4, we have taken the 


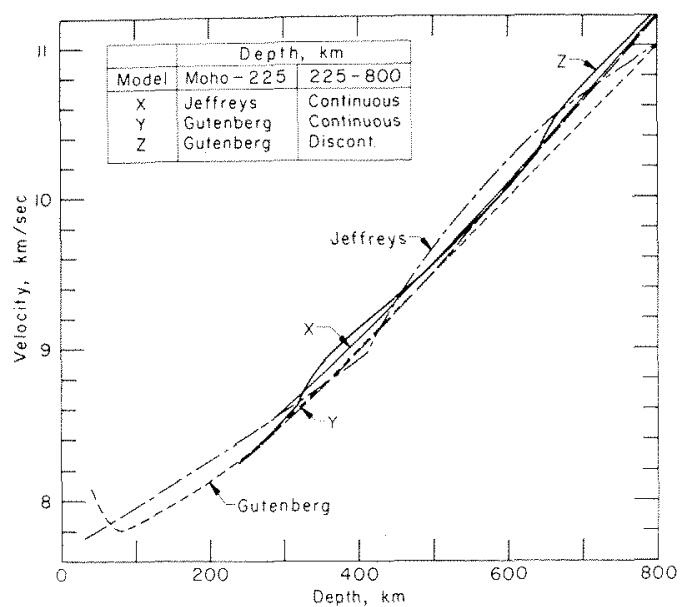

Fig. 4. Standard velocity-depth curves and three structures determined in this paper.

resulting two discontinuities of $\operatorname{model} Z$ to be of second order.

Any suggested earth model should obviously satisfy the observed travel times. The three models resulting from this study are based on measurements of $d t / d \Delta$, without direct reference to the absolute values of the transmission time. Indirectly, however, the computed distances have been influenced by the selection of a set of travel-time curves. The bias introduced by such a procedure is not expected to be more serious than other sources of error which exist in the evaluation of distances. Furthermore, with less-scattered data, it is possible to remove such bias by a process of successive approximation.

To examine the compatibility of the models with the travel times which are in common use, we have computed the variation of the transmission time with distance of these models for a focal depth of $33 \mathrm{~km}$ (see Anderson and Julian [1965]). A comparison of the results of the computed time of first arrivals and JeffreysBullen (JB) tables is made in Figure 5. The initial values of the residuals (at $\Delta=15^{\circ}$ ) can be explained by the difference in the crustal structures and also the difference between the Gutenberg and Jeffreys upper mantles (for models $Y$ and $Z$ ).

It can be seen from Figure 5 that models $X$ and $Z$ are in better agreement with JB tables than model $Y$. The residuals for model $Y$ remain positive throughout the distance range

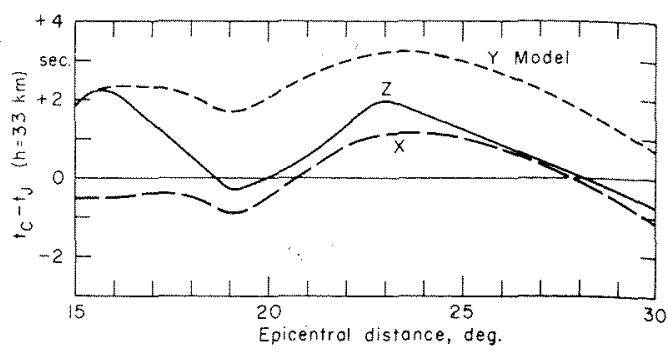

Fig. 5. Travel-time residuals from the JeffreysBullen tables for the three new velocity structures.

under consideration and attain a maximum value of $3.3 \mathrm{sec}$ at $\Delta=23.5^{\circ}$. The residuals of the other two models include both positive and negative values. The most conspicuous positive range, common in all three models, is at distances between about $21^{\circ}$ to $28^{\circ}$. The fact that positive anomalies are found for varying assumed models can be interpreted to indicate that for this region the JB travel times should be slightly increased (at least 1 see and possibly up to $2 \mathrm{sec}$ ) in this distance range. A comparison of the residuals of models $Y$ and $Z$, both of which have a Gutenberg upper mantle, indicates a preference for a discontinuous $d t / d \Delta$ variation, such as the one used to construct model $Z$, over a continuous one.

From $\Delta=28^{\circ}$ on, the residuals of $X$ and $Z$ become negative. Such a decrease, in all three models, is due to high $P$ wave velocities at depths near $800 \mathrm{~km}$ found here.

Uniqueness. Although we believe that the direct measurement and analysis of apparent velocity data is superior to the usual method of smoothing and differentiating travel-time data, particularly for the elucidation of fine structural details, there still remains a great deal of arbitrariness in the interpretation. In addition to the complications mentioned previously, there is the possibility that the three regions of the $P$ wave arrival data which we infer between $10^{\circ}$ and $30^{\circ}$ are three separate branches which contimue into the adjacent regions as later arrivals, perhaps even coaleseing to form cusps. Without using later arrivals and amplitude data it is impossible to discuss the sharpness of the discontinuities. While the gradient of velocity in each depth region is probably determined correctly, limited only by the scatter of the data, the details of the transition regions are not resolved. 


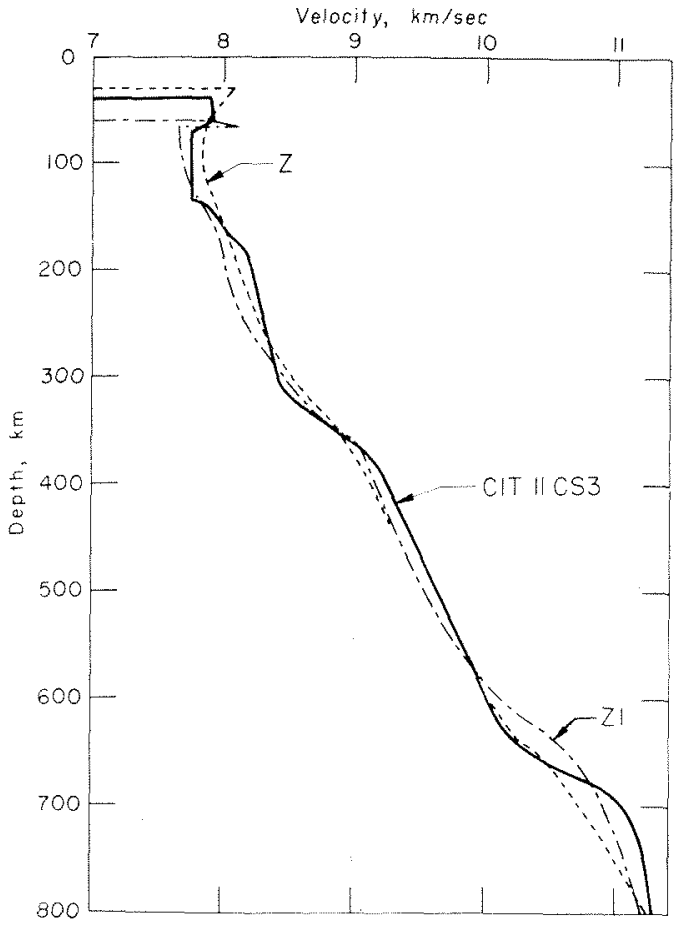

Fiv. 6. Model $Z$ and two other hypothetical mantle models.

Our method of analysis can be considered to give the smoothest variation of velocity consistent with our tripartite $\mathrm{dt} / \mathrm{d} \Delta$ curve. The model CIT11 [Anderson and Toksöz, 1963; Anderson, 1965] also has two major discontinuities at depths close to those determined here. Since this model was determined from surface waves, it is stepped rather than smooth and represents probably the coarsest variation of velocity consistent with surface wave data. The actual form of the discontinuities probably lies between these two extremes. The CIT11 model predicts multivalued travel-time curves over most of the interval between $14^{\circ}$ and $38^{\circ}$. Model $Z$ has only minor later-arriving branches. Because we cannot distinguish between these two kinds of models on the basis of first arrivals alone, we content ourselves here with a few numerical experiments, mainily in order to study the effect of the sharpness of the discontinuity. In Figure 6 we show model $Z$ and two additional models. CIT11CS3 is a smoothed version of CIT11. Model Z1 is a more abrupt version of model $Z$. Both differ from model $Z$

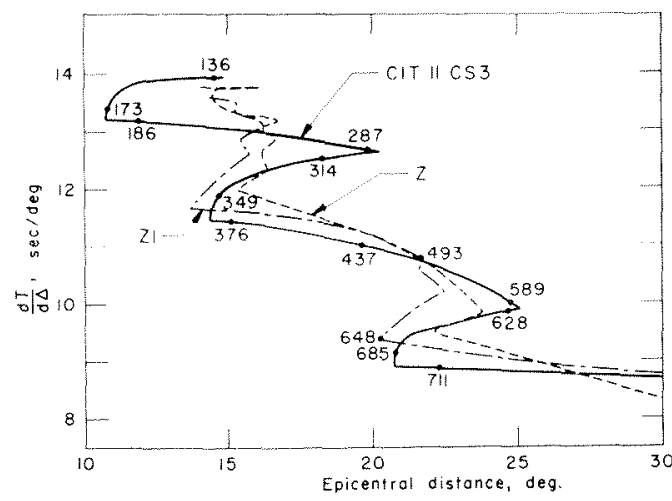

Fig. 7. Theoretical apparent reciprocal velocity curves for the models shown in Figure 6 . Numbers indicate the depths of penetration (in kilometers) for the rays emerging at various points.

primarily in the location and abruptness of the discontinuities. Neither is designed specifically to satisfy our present data but merely to illustrate the difficulty of interpretation when discontinuities are present. Figure 7 gives the computed $d t / d \Delta$ for these three models. Clearly, later arrivals must be used to determine details of transition zones.

Acknowledgment. This research was supported by the Advanced Research Projects Agency and was monitored by the Air Force Office of Scientific Research under contract AF 49(638)-1337.

\section{REFERENCES}

Anderson, D. L., Recent evidence concerning the structure and composition of the earth's mantle, Phys. Chem. Earth, 6, 1-131, 1965.

Anderson, D. L., and B. R. Julian, Travel times, velocities and amplitudes of body phases (abstract), presented at the annual meeting of Seismological Society of America, St. Louis, April 1965.

Anderson, D. L., and M. N. Toksöz, Surface waves on a spherical earth, 1, Upper mantle structure from Love waves, J. Geophys. Res., 68, 3483$3499,1963$.

Bullen, K. E., An Introduction to the Theory of Seismology, p. 223, Cambridge University Press, 1963.

Byerly, P., The Montana earthquake of June 28, 1925, Bull. Seismol. Soc. Am., 16, 209-265, 1926.

Byerly, P., The first preliminary waves of the Nevada earthquake of December 20,1932, Bull. Seismol. Soc. Am., 25, 62-80, 1935.

Doyle, H. A., and J. P. Webb, Travel times to Australian stations from Pacific nuclear explosions in 1958, J. Geophys. Res., 68, 1115-1120, 1963.

Jeffreys, H., and K. E. Bullen, Seismological Ta- 
bles, British Association for the Advancement of Science, 1958.

Gutenberg, B., The asthenosphere low-velocity layer, Ann. Geofis, 12, 439-460, 1959.

Lehmann, $\mathrm{I}$., On the travel times of $P$ as determined from nuclear explosions, Bull. Seismol. Soc. Am. 54, 123-139, 1964.

Warren, D. H., J. C. Roller, and W. H. Jackson,
A seismic-refraction survey in the vicinity of the Tonto Forest Seismological Observatory, Arizona (abstract), Trans. Am. Geophys. Union, $46,155,1965$.

(Manuscript received May 21, 1965; revised June 29, 1965. 